ISSN $2230-8695$

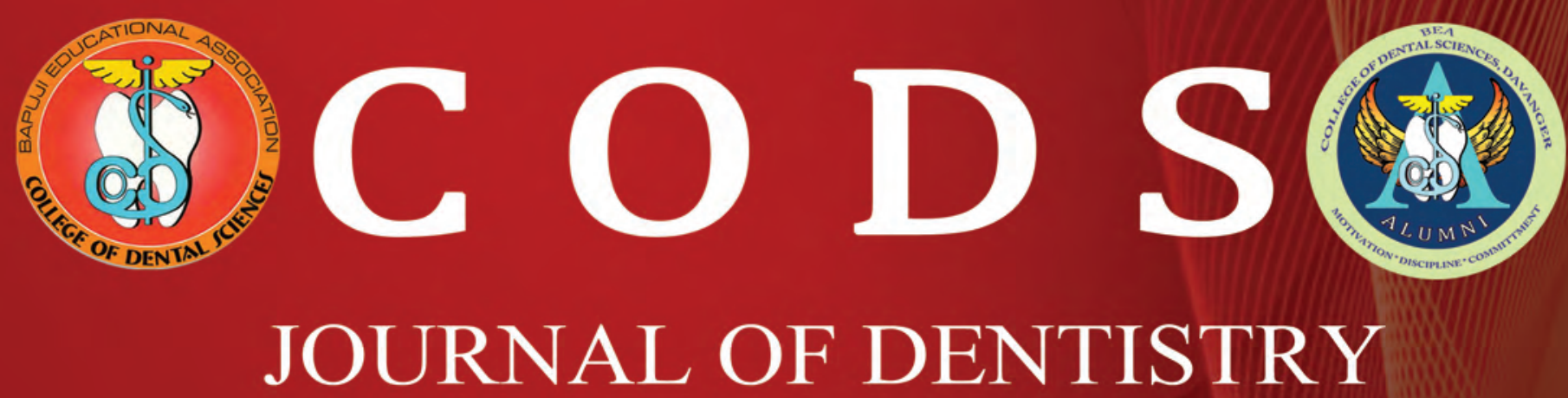

Official Publication of College of Dental Sciences Alumni Association, Davangere.

Volume $6 \cdot$ Issue $1 \bullet 2014$ 


\section{CODS Journal of Dentistry}

Official Publication of College of Dental Sciences Alumni Association, Davanagere

Volume 6, Issue 1, 2014

\section{CONTENTS}

Director's Message

V.V. Subba Reddy

President's Message

Vasundhara Shivanna

Secretary's Message

Praveen S. Basandi

Editorial

Nandini D.B

\section{Original Articles}

Effect of alcohol containing and alcohol free mouth rinses on microhardness of three esthetic restorative materials

Vasundhara Shivanna, Rucha Nilegaonkar

Prevalence and distribution of dental anomalies and fluorosis in a small cohort of

Indian school children and teenagers

Selvamani. M, Praveen S Basandi, Madhushankari G.S

\section{Review Articles}

Paperless dentistry - The future

Mala Ram Manohar, Gajendra Bhansali

Photo activated disinfection in restorative dentistry - A technical review

Deepak B.S, Mallikarjun Goud K, Nishanth P

An overview of occupational hazards in dental practice and preventive measures.

Poorya Naik .D.S, Chetan .S, Gopal Krishna.B.R, Naveen Shamnur

An overview on influences of estrogen and progesterone on periodontium 


\section{CODS Journal of Dentistry}

Official Publication of College of Dental Sciences Alumni Association, Davanagere

\section{Volume 6, Issue 1, 2014}

\section{CONTENTS}

\section{Review Articles}

Dental home - A new approach for child oral health care

Poornima P, Meghna Bajaj, Nagaveni N.B, Roopa K.B, V.V. Subba Reddy

Variants of inferior alveolar nerve block: A review

Anuradha M, Yashavanth Kumar D.S, Harsha .V. Babji, Rahul Seth

\section{Case Reports}

Ellis-van Creveld syndrome affecting siblings: A case report and review

Mamatha G.P, Manisha Jadhav , Rajeshwari G Annigeri, Poornima .P, V.V Subba Reddy

Integrated approach of ceramic and composite veneers in tetracycline

stained teeth: A case report.

Divya K.T, Satish .G

Fibrous dysplasia of right maxilla: A case report and review of literature

Guruprasad .L, Kavita Rao, Uma Devi H.S, Priya N.S

A case report of recurrent herpetic gingivostomatitis; with special reference to the role of cytology in diagnosis

Pramod K Jali, Nandini D.B, Mohan K.P, Madhushankari G.S

Eagle's syndrome with type III segmented styloid process : A case report.

Usha V. A, Mamatha G. P, Maria Priscilla David, 


\title{
Ellis-van Creveld syndrome affecting siblings: A case report and review
}

\author{
Mamatha G.P.', Manisha Jadhav², Rajeshwari G. Annigeri³, Poornima P.4, V.V. Subba Reddy ${ }^{5}$,
}

Professor ${ }^{1}$, Postgraduate Student ${ }^{2}$, Professor and Head ${ }^{3}$ Department of Oral Medicine and Radiology, College of Dental Sciences, Davangere. Professor and Head ${ }^{4}$ Department of Pedodontics, College of Dental Sciences, Davangere.

Director ${ }^{5}$, College of Dental Sciences, Davangere.

\begin{abstract}
:
Ellis-van Creveld syndrome (EVC) is a genetic disorder that was first described by Richard Ellis and Simon van Creveld in 1940. EVC is a rare autosomal recessive disease resulting from a genetic defect located in chromosome 4p16. The name chondroectodermal is used as it affects both the skeleton (chondro) and the skin (ectoderm).The four principal characteristics are chondrodysplasia, polydactyly, ectodermal dysplasia and congenital heart defects. The patients have small stature, short limbs, fine sparse hair and hypoplastic nails. The orofacial manifestations include multiple gingivolabial musculofibrous frenule, dental anomalies like hypodontia associated with malocclusion. This entity can be diagnosed at any age, even during pregnancy. The differentiation should be made between Asphyxiating Thoracic Dysplasia (Jeune syndrome) and other orofaciodigital syndromes. A multidisciplinary approach is required to manage this condition. We are reporting a rare clinical entity of chondroectodermal dysplasia with classical signs affecting siblings who reported to the Department of Oral Medicine and Radiology with review of its literature.
\end{abstract}

Keywords: Ellis-van Creveld syndrome, orofacial anomalies, chondrodysplasia, polydactyly, asphyxiating thoracic dysplasia.

\section{Introduction:}

Ellis-van Creveld syndrome (EVC) is a genetic disorder that was first described by Richard Ellis and Simon van Creveld in 1940. EVC is a rare autosomal recessive disease resulting from a genetic defect located in chromosome $4 \mathrm{p} 16^{1-3}$. The name chondroectodermal is used as it affects both the skeleton (chondro) and the skin (ectoderm). The four principal characteristics are chondrodysplasia, polydactyly, ectodermal dysplasia and congenital heart defects. The patients have small stature, short limbs, fine sparse hair and hypoplastic nails ${ }^{4}$. The orofacial manifestations include multiple gingivolabial musculofibrous frenule, dental anomalies like hypodontia associated with malocclusion. This entity can be diagnosed at any age, even during pregnancy. A multidisciplinary approach is required to manage this condition.

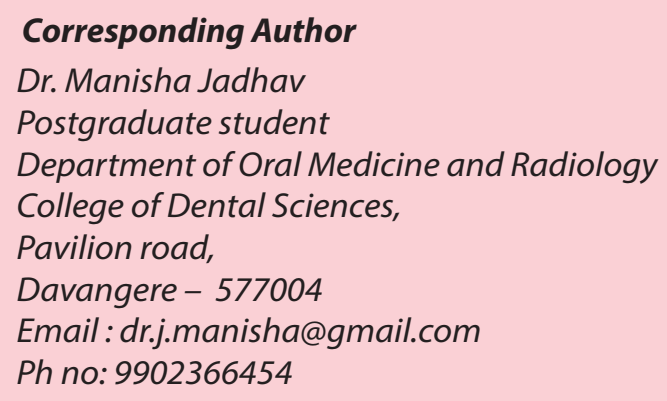

\section{Case report:}

A 13 year old female patient reported with a complaint of missing teeth in the lower front teeth region of the jaw since the exfoliation of the single natal tooth. The history revealed that the patient's parents had consanguious marriage and were first degree cousins, further the patient was a full term baby with low birth weight and height as compared to the normal children of her age. There was also a history of affected younger sibling of small stature, delayed eruption and missing teeth and polydactyly. (Fig 9).

On general physical examination the patient had a stunted growth with a weight of $26.5 \mathrm{kgs}$, height of $126 \mathrm{cms}$ and had normal intelligence. The face showed frontal bossing, depressed malar region, short philtrum, non-prominent vermillion border of upper lip, sparse and thin eyebrows, decreased facial height, small and cup shaped posteriorly placed ears, upward slanted eyes and flat nasal bridge. Hair and skin was normal except for sparse eyebrows and had normal sweating. The extremities were plump and showed acromelic and mesomelic shortness of the limbs (Fig 1). There was bilateral post axial polydactyly on the upper limbs. The nails were hypoplastic, thin, spoon shaped and even absent on the extra digits (Fig 2). Genu valgum was seen as a result of the abnormal proximal tibial epiphysis. 
Intraoral examination showed numerous anomalies, the pathognomic being the fusion of the middle portion of the upper and the lower lip to the maxillary and mandibular gingival mucosal margin respectively, so that there was absence of mucobuccal fold. Multiple musculofibrous frenule were present. Bilateral gingival clefts were present distal to upper central incisors. On hard tissue examination, upper lateral and lower central and lateral incisors were missing along with increased cervico-incisal length, distal tilt and 180 degree rotation of the upper central incisors. Microdontia was present in relation to upper premolars and multiglobular occlusal surface of lower first and second molars.

There was generalized hypoplasticity of the dentition and right and left side posterior cross bite was present (Fig 3).

Orthopantomograph revealed a horizontally impacted tooth in the lower front alveolar region of the jaw which presented as a tender swelling clinically and the tooth buds for upper lateral incisors, upper left third molar and lower incisors were missing (Fig 4).

Complete skeletal survey was done for the patient. Apart from the dental radiographs, chest (Fig 5), hand wrist,

upper limb, lateral spine and pelvis with femur were taken. Exostosis involving the upper 1/3rd of the right tibia was seen (Fig 6). Right side hand wrist radiograph showed ulnar polysyndactyly and polydactyly on left (Fig 7). No cardiac abnormality was reported on examination by the cardiologist and no other organ deformity was reported on ultrasonography.

\section{Discussion:}

Ellis-van Creveld syndrome (EVC) is a rare condition involving oral, dermal, skeletal system and many a times congenital cardiac defects. The EVC gene is localized by linkage analysis to the distal short arm of chromosome 4 with five different mutations ${ }^{5,6}$. Affected individuals with mutation in EVC1 and EVC2 are phenotypically indistinguishable ${ }^{7}$. The autosomal recessive transmission most often described history of consanguinity as so in our case and also affected siblings (Fig. 9) suggestive of genetic defect expressing phenotypically.

It is a rare disorder and a wide variation in prevalence rate could be attributed to bias in reporting worldwide. The most striking features of EVC reported in the literature include bilateral postaxial polydactyly of the hands, ectodermal dysplasia affecting the nails and teeth and congenital heart abnormalities ${ }^{8}$ and chondrodysplasia of long bone resulting in acromelic dwarfism and presence of Genu valgum. 1/3rd of these patients die in infancy from cardiac and respiratory problems and those who survive require multidisciplinary approach for treatment. EVCs may be detected prenatally by ultrasonographic examination. The various associated structural defects in late first trimester, including narrow thorax, polydactyly, rounded metaphysic and cardiac abnormalities may suggest the diagnosis EVCs. Congenital heart malformations occurring in about $50-60 \%$ of cases and comprising of single atrium, defects of the mitral and tricuspid valves, patent ductus, ventricular septal defect, atrial septal defect. ${ }^{3}$

The oral manifestations shows, spectrum of findings such as malocclusion, labiogingival adherence, gingival hypertrophy, accessory labiogingival frenulae, serrated incisal margins, dental transpositions, diastema, conical teeth, enamel hypoplasia and hypodontia. Teeth may be prematurely erupted at birth or exfoliated prematurely. The present case showed hypoplastic nails, short stature, polydactyly with synostosis along with anodontia and malaligned teeth, musculofibrous frenula and gingival clefts with normal cardia.

Presently the patient is undergoing treatment for malocclusion and missing teeth in the Department of Pedodontics and Preventive Dentistry (Fig. 8).

\section{Conclusion:}

Management of such patients during the neonatal period is mostly symptomatic. Orthopedic follow up is required to manage the bone deformity; professional dental care should be considered for management of the oral manifestations. Early treatment can prevent the patient from various complications and undue psychological trauma further they require genetic counseling.

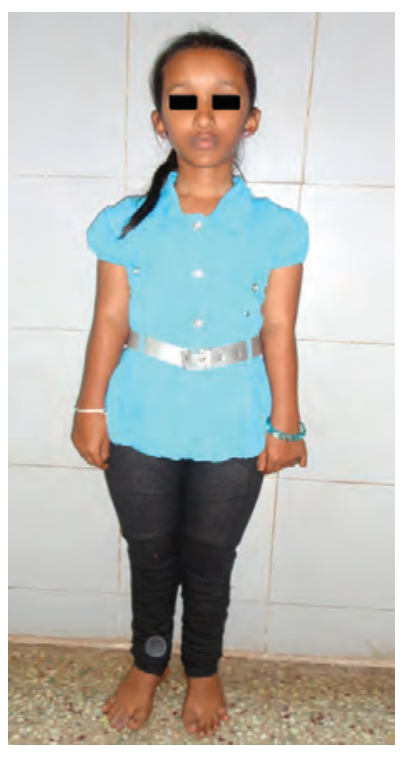

Fig 1: Patient aged 13 years showing short stature 

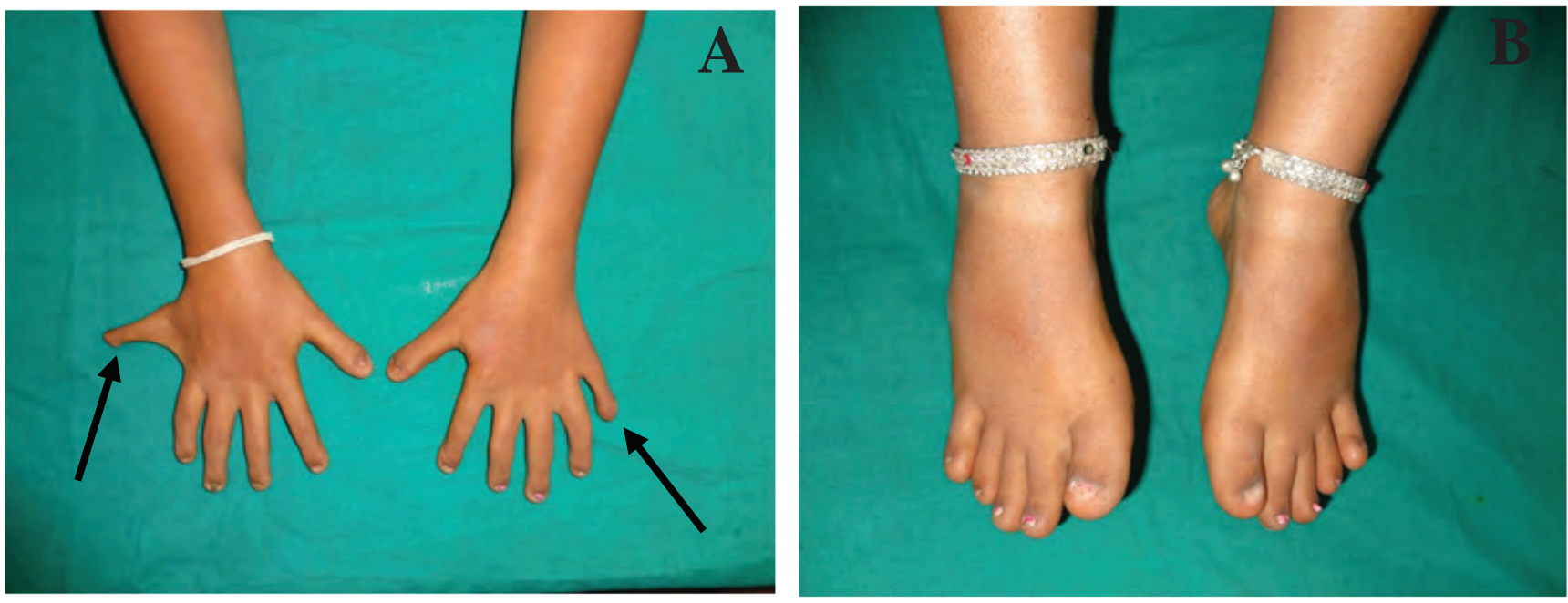

Fig 2: Photographs of upper (A) and lower limbs (B).

A) Upper limbs showing bilateral post-axial polydactyly (Black arrow).
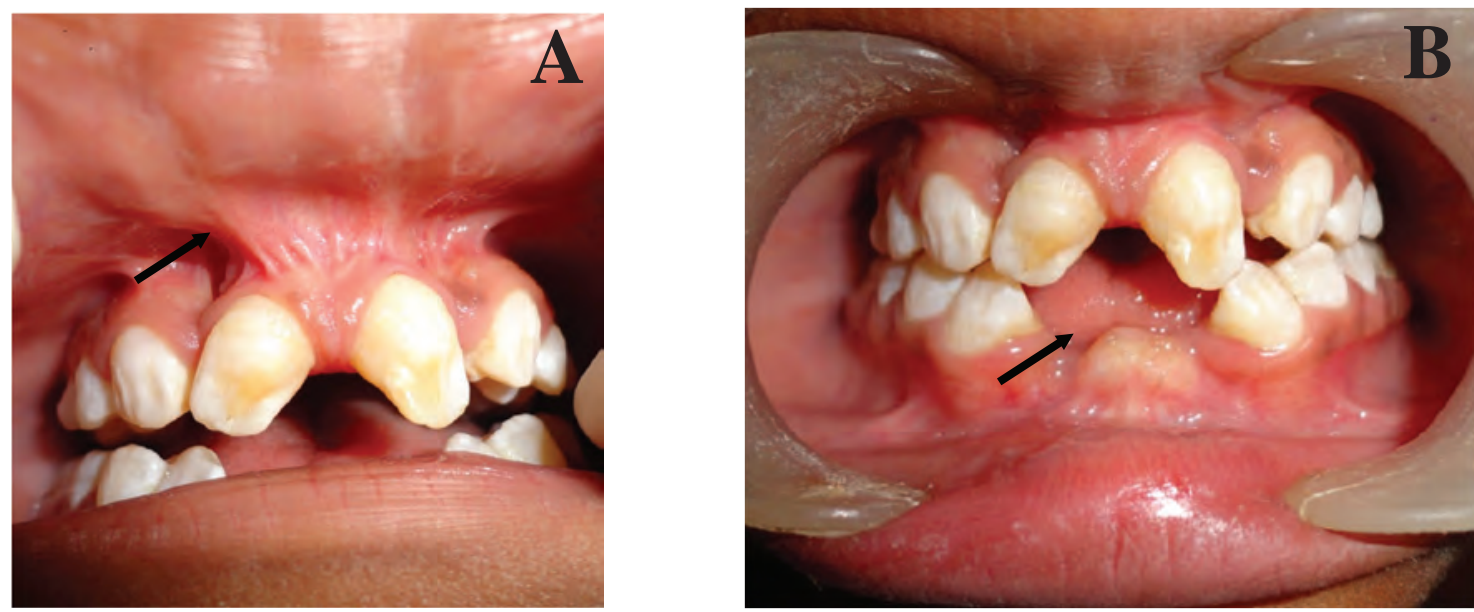

Fig3: Intraoral photographs showing A) multiple labial frenulae, and B) hypodontia (Black arrow).

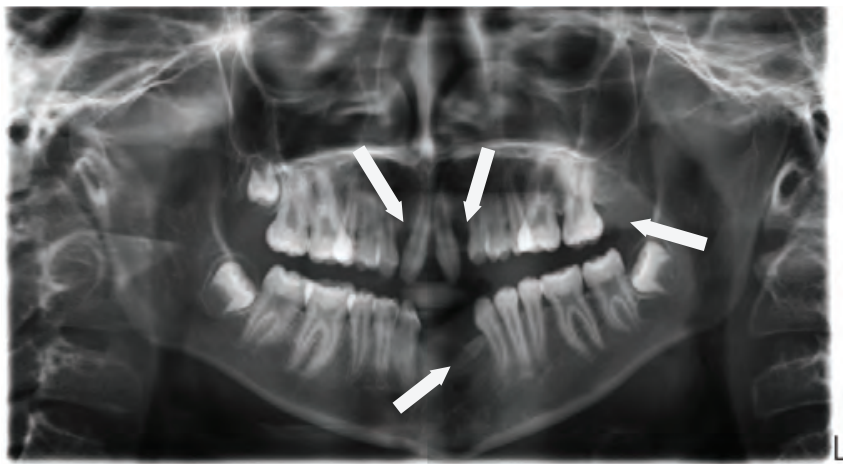

Fig 4: Orthopantamograph showing hypodontia and impacted tooth in anterior mandibular region (white arrows).

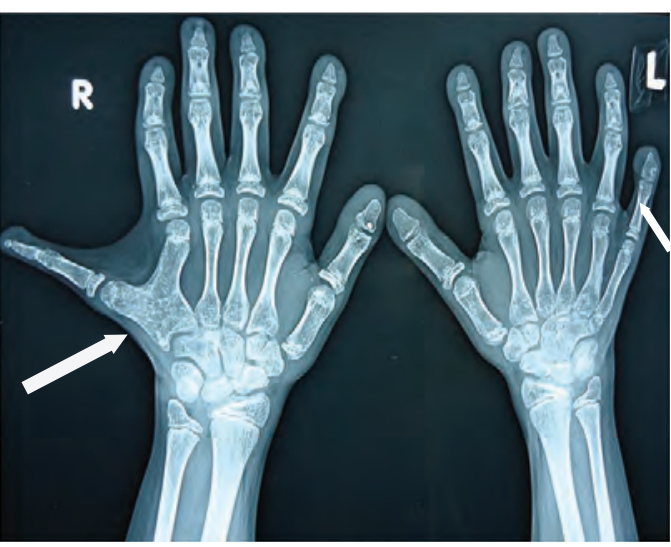

Fig 5: Hand wrist radiograph showing right side syndactyly and polydactyly on left side (white arrows). 


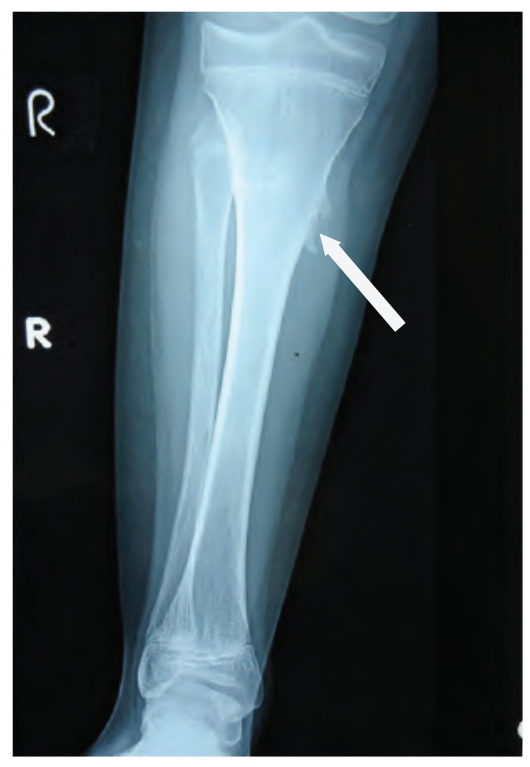

Fig 6: Exostosis involving upper 1/3rd of right tibia (white arrow).

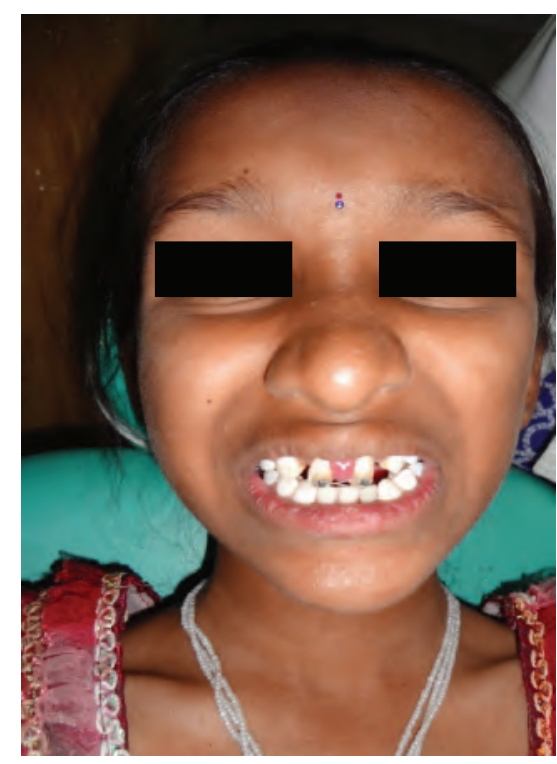

A

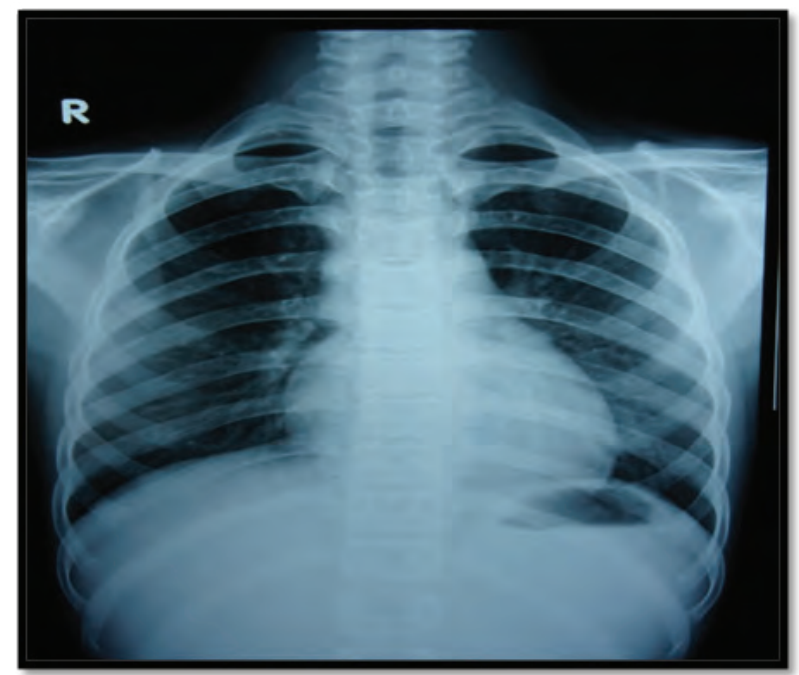

Fig 7: Normal chest radiograph.

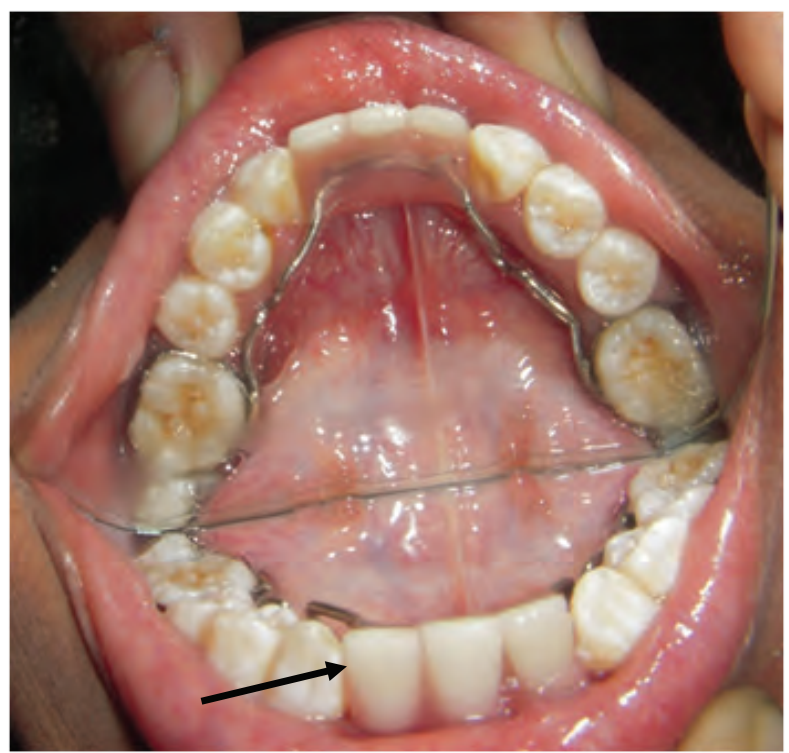

B

Fig 8: Post treatment photographs

A- Derotation and mesial tilting of upper central incisors using elastomeric module. B- Modified lingual arch placement with replacement for lower central incisors. 


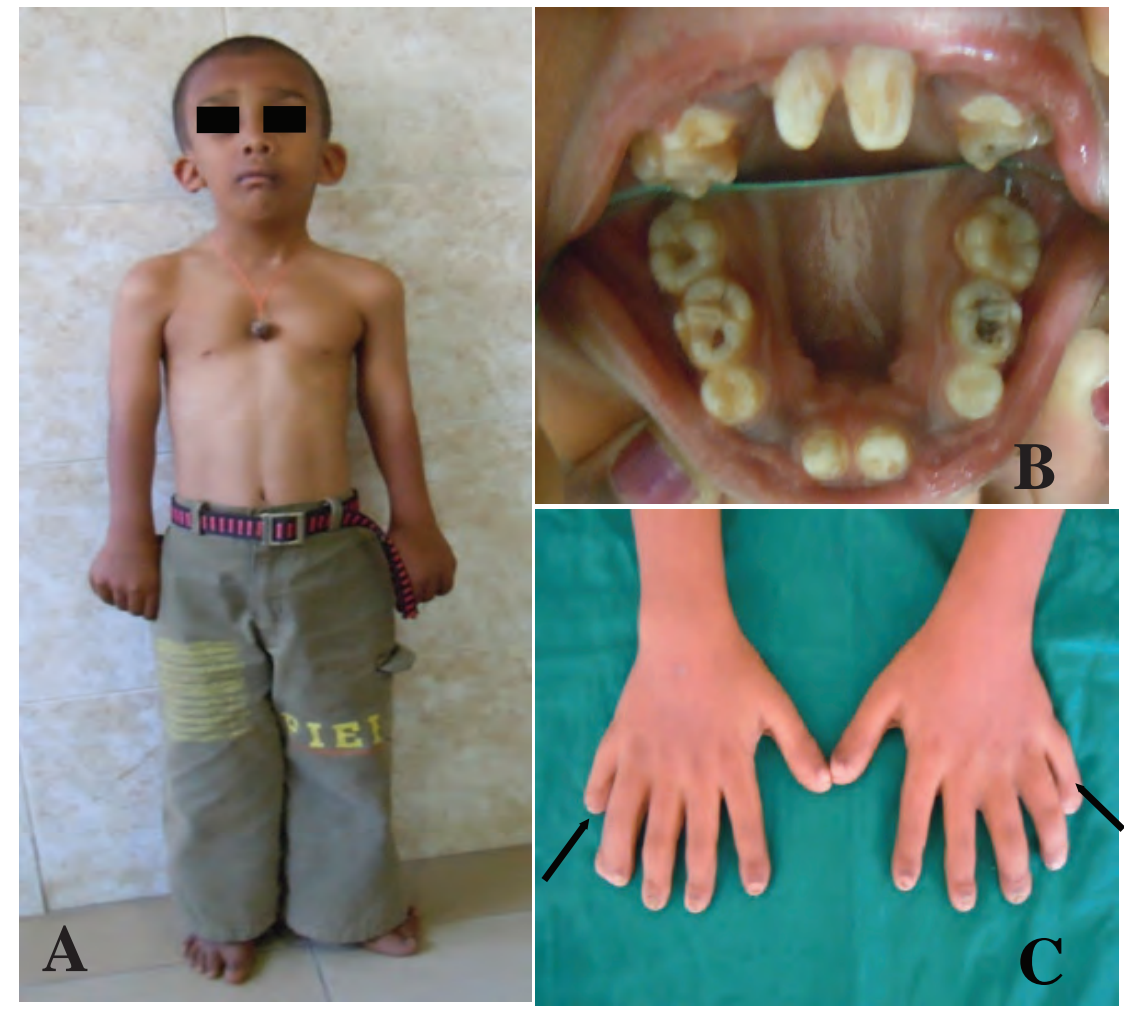

Fig 9: Photographs of the sibling.

A- Complete profile picture of the patient showing short stature.

B- Maxillary arch showing hypodontia.

C- Upper limbs showing poly and syndactyly.

\section{References:}

1. Arya L, Mendiratta V, Sharma RC, Solanki RS. Ellis-van Creveld Syndrome: A report of two cases. Pediatr Dermatol.2001;18:485-9.

2. Tompson SW, Ruiz-Perez VL, Blair HJ, Barton S, Navarro V, Robson JL, et al. Sequencing EVC and EVC2 identifies mutations in two-thirds of Ellis-van Creveld syndrome patients. Hum Genet. 2007;120:663-70.

3. Baujat G, Le Merrer M. Ellis-van Creveld syndrome. Orphanet J Rare Dis. 2007;2:27.

4. Kurian K, Shanmugam S, Harshuardhas T.

Chondroectodermal dysplasia (Ellis van Creveld syndrome): A report of three cases with review of literature. Indian J Dent Res 2007;18(1): 31-4.

5. Francomano CA, Ortez De Luna R, Ide SE, Pyeritz RE, Wright M, Polymeropoulos MH. The gene for Ellis -van Creveld syndrome maps to chromosome 4p16. Am J Hum Genet 1995; 579(suppl): the A191.

6. Polymeropoulos MH, Ide SE, Wright M, Goodship J, Weissenbach J, Pyeritz RE, Da Silva EO, Ortiz De Luna RI, Francomano CA. The gene for the Ellis-van Creveld syndrome is located on chromosome 4p16. Genomics. 1996;35(1):1-5.
7. Ruiz-Perez VL, Tompson SW, Blair HJ, Espinoza-Valdez C, Lapunzina P, Silva EO, Hamel B,Gibbs JL, Young ID, Wright MJ, Goodship JA.Mutations in two nonhomologous genes in ahead-to-head configuration cause Ellis-van Creveld syndrome. Am J Hum Genet. 2003 Mar; 72(3):728-32.

8. Gorlin RJ, Cohen MM Jr, Levin LS. Syndromes of the head and neck. 3rd ed. New York: Oxford Univ Press, $1990 ; 201-4$.

\section{How to cite this article:}

Mamatha GP, Manisha J, Rajeshwari GA, Poornima P, Subba Reddy VV. Ellis-van Creveld syndrome affecting siblings - A case report and review. CODS J Dent 2014;6;40-44

Source of support: Nil. Conflict of interest: None Declared. 